\title{
PENGARUH PEMAHAMAN PERATURAN PERPAJAKAN, TARIF PAJAK, DAN KUALITAS PELAYANAN TERHADAP KEPATUHAN WAJIB PAJAK (Studi Kasus pada Wajib Pajak Orang Pribadi Non Karyawan di KPP Pratama Cibinong Periode 2020)
}

\author{
Nabilla Karlinda Raharjo ${ }^{1}$ \\ Majidah $^{2}$ \\ Kurnia ${ }^{3}$
}

\author{
Fakultas Ekonomi dan Bisnis Universitas Telkom, Jawa Barat, Indonesia ${ }^{1,2,3}$ \\ Email: nabillakarlinda@student.telkomuniversity.ac.id ${ }^{1}$
}

\begin{abstract}
Taxes are the source of state revenue which gives the biggest contribution in supporting the state budget. However, state revenue from taxes in Indonesia is not optimal. This optimization is due to the low level of compliance of taxpayers in carrying out their tax obligations. The purpose of this study was to determine the effect of understanding tax regulations, tax rates, and service quality on Taxpayers Obedience simultaneously and partially. Non-Employee Individual Taxpayers who are registered as SPT compliant in KPP Pratama Cibinong are the population in this study. This study uses convenience sampling with a total sample of 72 people. The data of this study were analyzed with descriptive statistical analysis and multiple linear regression analysis. The results showed that partially, only tax rates and service quality were affected by taxpayers obedience. While simultaneously, understanding taxation regulations, tax rates, and service quality affects the obedience of taxpayers.
\end{abstract}

Keywords: $\quad$ Taxpayers Obedience; Understanding Taxation Regulations; Tax Rates; Service Quality; Non-Employee Individual Taxpayers.

\begin{abstract}
ABSTRAK
Pajak merupakan sumber pendapatan negara yang memberikan kontribusi terbesar dalam mendukung APBN. Namun, penerimaan negara dari pajak di Indonesia belum optimal. Ketidakoptimalan tersebut karena masih rendahnya tingkat kepatuhan Wajib Pajak dalam melaksanakan kewajiban perpajakannya. Tujuan penelitian ini adalah untuk mengetahui pengaruh pemahaman peraturan perpajakan, tarif pajak, dan kualitas pelayanan terhadap Kepatuhan Wajib Pajak secara simultan dan parsial. Wajib Pajak Orang Pribadi Non Karyawan yang tercatat wajib SPT di KPP Pratama Cibinong merupakan populasi dalam penelitian ini. Penelitian ini menggunakan convenience sampling dengan jumlah sampel sebanyak 72 orang. Data penelitian ini dianalisis dengan analisis statistik deskriptif dan analisis regresi linier berganda. Hasil penelitian menunjukkan bahwa secara parsial, yang mempengaruhi kepatuhan Wajib Pajak hanya tarif pajak dan kualitas pelayanan. Sedangkan secara simultan, pemahaman peraturan perpajakan, tarif pajak, dan kualitas pelayanan berpengaruh terhadap kepatuhan Wajib Pajak.
\end{abstract}

Kata Kunci: Kepatuhan Wajib Pajak; Pemahaman Peraturan Perpajakan; Tarif Pajak; Kualitas Pelayanan; Wajib Pajak Orang Pribadi Non Karyawan. 


\section{PENDAHULUAN}

Pajak adalah partisipasi dari rakyat kepada negara yang didasarkan undangundang, bersifat memaksa dan dipakai untuk membiayai pengeluaran negara (Salsabila dkk, 2019). Pajak juga merupakan sumber pendapatan negara yang memberikan kontribusi terbesar dalam mendukung pembiayaan APBN yang disajikan pada Tabel 1

Tabel 1.

Penerimaan Pajak pada APBN Tahun 2015 s/d 2019 (dalam Triliun)

\begin{tabular}{cccccc}
\hline No & Tahun & \begin{tabular}{c} 
Jumlah \\
Penerimaan \\
\cline { 3 - 5 }
\end{tabular} & $\begin{array}{c}\text { Penerimaan } \\
\text { Negara dari } \\
\text { Pajak }\end{array}$ & $\begin{array}{c}\text { Penerimaan } \\
\text { Negara Bukan } \\
\text { Pajak }\end{array}$ & $\begin{array}{c}\text { Persentase } \\
\text { Penerimaan Pajak }\end{array}$ \\
\hline 1 & 2015 & 1793,6 & 1201,7 & 591,9 & $67 \%$ \\
\hline 2 & 2016 & 1822,5 & 1546,7 & 275,8 & $84 \%$ \\
\hline 3 & 2017 & 1750,3 & 1498,9 & 251,4 & $86 \%$ \\
\hline 4 & 2018 & 1894,7 & 1618,1 & 276,6 & $85 \%$ \\
\hline 5 & 2019 & 2165,1 & 1786,4 & 378,7 & $82 \%$ \\
\hline
\end{tabular}

Sumber: www.kemenkeu.go.id, diolah oleh Penulis (2020).

Penerimaan pajak terhadap APBN berfluktuasi setiap tahunnya. Walaupun berfluktuasi, penerimaan pajak terhadap APBN dalam 5 tahun terakhir selalu mencapai angka di atas rata - rata 50\%. Namun, fakta menunjukkan bahwa realisasi penerimaan perpajakan di Indonesia hingga November 2019 hanya mencapai 73,5\% atau sebesar Rp1312,4 Triliun dari target yang ditetapkan dalam APBN sebesar Rp1786,4 Triliun (Friana, 2019). Dengan demikian, pemerintah dan Dirjen Pajak harus terus berusaha untuk meningkatkan penerimaan negara dari pajak agar mencapai target setiap tahunnya. 
Salah satu upaya pemerintah untuk memaksimalkan penerimaan perpajakan adalah dengan melakukan reformasi perpajakan, yaitu mengubah sistem perpajakan dari official assessment system menjadi self-assessment system. Pada sistem ini, pemerintah hanya mengawasi apakah pajak yang dilaporkan telah sesuai berdasarkan penghasilan wajib pajak yang diterima, sehingga pelaksanaan sistem tersebut sangat bergantung pada kepatuhan Wajib Pajak dalam melaksanakan kewajiban perpajakan (Pratiwi, 2016).

Kepatuhan Wajib Pajak merupakan perilaku patuh dan sadar pada pembayaran dan pelaporan masa dan tahunan sesuai dengan peraturan perpajakan yang berlaku (www.klikpajak.id). Apabila Wajib Pajak tidak mematuhi peraturan perpajakan tersebut, akan berdampak pada penurunan penerimaan negara, sehingga meningkatkan kepatuhan wajib pajak, perlu menjadi agenda utama Dirjen Pajak (www.klikpajak.id).

Namun, fakta menunjukkan bahwa tingkat kepatuhan wajib pajak di Indonesia masih dikatakan rendah, yaitu hanya mencapai $67,2 \%$ atau sebesar 12,3 Juta Wajib Pajak yang menyampaikan SPT dari 18,3 Juta jumlah Wajib Pajak yang wajib menyampaikan SPT sampai dengan Juli 2019. Data otoritas pajak juga menunjukkan bahwa Wajib Pajak Orang Pribadi (WPOP) Non Karyawan merupakan jenis Wajib Pajak yang menyampaikan SPT dengan tingkat kepatuhan terendah yaitu hanya mencapai sebesar 42,75\% (Suwiknyo, 2019). Fakta lain juga menunjukkan, sesuai dengan data KPP Pratama Cibinong, WPOP Non Karyawan memiliki tingkat kepatuhan terendah dibandingkan dengan Wajib Pajak lainnya. Berikut terlampir 
perbandingan rasio kepatuhan Wajib Pajak di KPP Pratama Cibinong.

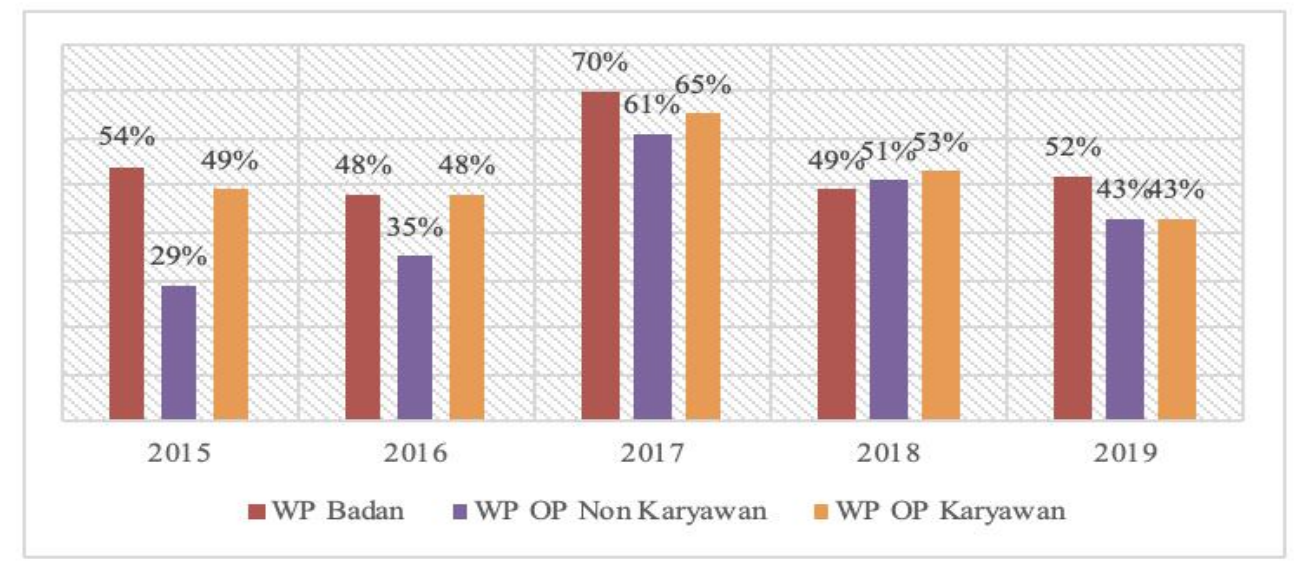

\section{Gambar 1. \\ Perbandingan Rasio Kepatuhan Wajib Pajak di KPP Pratama Cibinong}

Sumber: KPP Pratama Cibinong, diolah oleh Penulis (2020).

Kepatuhan Wajib Pajak yang terdaftar di KPP Pratama Cibinong dari tahun 2015 sampai dengan tahun 2019 menunjukkan, WPOP Non Karyawan memiliki tingkat kepatuhan terendah dengan rata - rata 43,8\% dibandingkan Wajib Pajak lainnya, yaitu Wajib Pajak Orang Pribadi Karyawan sebesar 51,6\% dan Wajib Pajak Badan sebesar 54,6\%. Tinggi atau rendahnya kepatuhan Wajib Pajak dapat disebabkan oleh beberapa faktor (www.pajak.go.id): a) Struktur Wajib Pajak yang tercatat wajib SPT didominasi oleh WPOP Karyawan, sehingga rasio kepatuhan WPOP Non Karyawan tidak mencapai realisasi penyampaian SPT secara signifikan; b) Masih banyak Wajib Pajak yang terdaftar belum memenuhi kewajiban objektif (penghasilan Wajib Pajak di bawah Penghasilan Tidak Kena Pajak); c) Data internal (seperti Approweb dan aplikasi portal DJP) dan data eksternal atas Wajib Pajak yang tidak menyampaikan SPT belum dimanfaatkan secara optimal; d) Masih rendahnya 
kesadaran Wajib Pajak untuk melaksanakan kewajiban perpajakannya; dan faktor lainnya yakni pemahaman peraturan perpajakan, tarif pajak, dan kualitas pelayanan. Adanya ketidakkonsistenan beberapa hasil penelitian tentang faktor - faktor yang mempengaruhi kepatuhan Wajib Pajak baik secara simultan maupun parsial.

Pemahaman Peraturan Perpajakan. Pemahaman peraturan perpajakan ialah cara wajib pajak untuk memahami peraturan perpajakan dan dapat melaksanakannya sesuai dengan ketentuan yang berlaku (Mustofa, 2016). Self-assessment system merupakan sistem pemungutan pajak yang dianut di Indonesia, yang dimana Wajib Pajak diberi kewenangan untuk menghitung, membayar dan melaporkan sendiri besar pajaknya. Maka dari itu, Wajib Pajak harus mengetahui dan memahami peraturan perpajakan yang diberlakukan agar dapat melaksanakan kewajibannya dengan baik. Apabila Wajib Pajak tidak mengetahui peraturan perpajakan, mereka tidak memahami kewajiban sebagai Wajib Pajak sehingga membuat mereka tidak patuh (Mahfud, 2017). Penelitian sebelumnya menyatakan bahwa pemahaman peraturan perpajakan berpengaruh positif terhadap kepatuhan Wajib Pajak (As'ari \& Erawati, 2018); dan juga hasil penelitian (Priambodo, 2017).

Tarif pajak adalah tarif yang dipakai untuk menentukan besarnya pajak yang wajib dibayarkan (Rahayu, 2017). Tarif pajak memiliki hubungan yang erat dengan fungsi pajak, salah satunya fungsi mengatur (regulerend) yang dimana fungsi tersebut sebagai kebijakan dan usaha pemerintah untuk mengatur perekonomian negara, sehingga besarnya tarif pajak yang ditetapkan dalam undang - undang perpajakan 
didasarkan pada keadaan perekonomian negara. Hal ini juga menunjukkan bahwa tarif pajak dilandaskan atas pemahaman setiap orang yang mempunyai hak sama sehingga tercapai tarif pajak yang proporsional. Apabila terjadi kesalahan persepsi dalam menentukan besarnya tarif pajak, hal ini dapat merugikan negara (Tawas dkk, 2016). Semakin pemerintah adil dalam menetapkan besarnya tarif pajak, Wajib Pajak akan semakin memahami persepsi terhadap tarif pajak yang diberlakukan, sehingga semakin tinggi pula kepatuhan Wajib Pajak dalam melaksanakan kewajiban perpajakannya (Lazuardini, 2018). Penelitian sebelumnya menyatakan bahwa tarif pajak berpengaruh positif terhadap kepatuhan Wajib Pajak (Tawas dkk, 2016); dan hasil penelitian (Ananda dkk, 2015).

Kualitas pelayanan merupakan pelayanan yang diberikan kepada Wajib Pajak yang dilakukan secara terus menerus dan sesuai ketentuan yang berlaku (Susmita, 2016). Pelayanan Perpajakan didasarkan oleh beberapa standar kualitas yaitu kualitas SDM, sistem informasi perpajakan, dan ketentuan perpajakan. Pelayanan yang diberikan pemerintah akan mempengaruhi kehadiran dan kepuasan Wajib Pajak untuk melaksanakan kewajiban perpajakannya, sehingga kualitas pelayanan harus ditingkatkan dengan memberikan pelayanan yang baik kepada Wajib Pajak (Lubis, 2017). Hal ini sesuai dengan Surat Edaran Direktur Jenderal Pajak Nomor SE09/PJ/2013 tentang Panduan Pelayanan Prima Dirjen Pajak. Oleh karena itu, pemerintah harus memberikan pelayanan yang berkualitas yang nantinya mampu meningkatkan kepatuhan Wajib Pajak (Erlina dkk, 2018). Penelitian sebelumnya 
menyatakan bahwa kualitas pelayanan berpengaruh positif terhadap kepatuhan Wajib Pajak (Susmita, 2016); dan juga hasil penelitian (Erlina dkk, 2018).

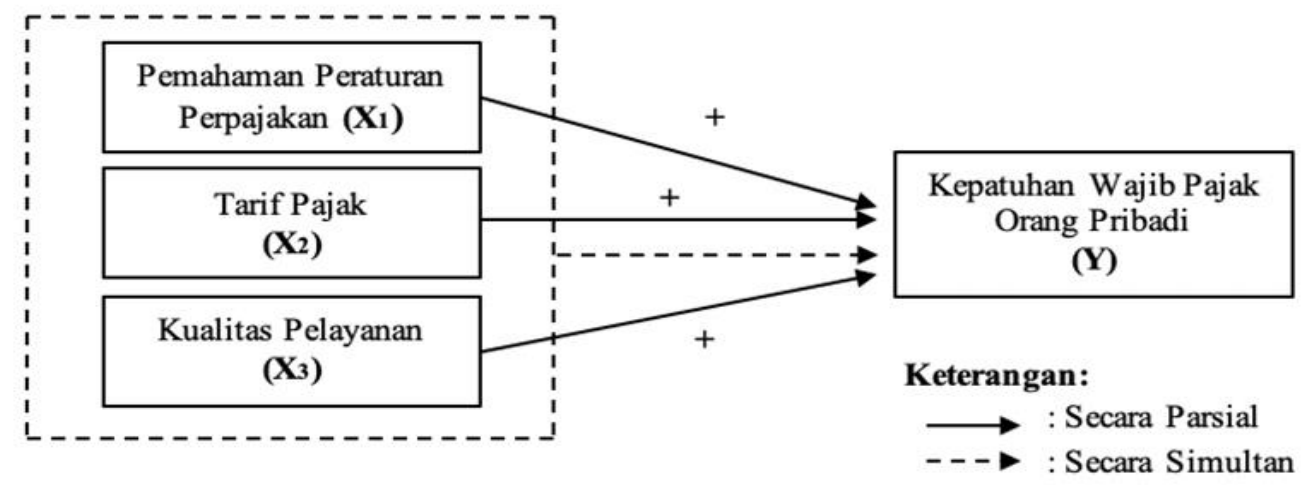

Gambar 2. Kerangka Pemikiran

Sumber: Olahan Penulis (2020).

Berdasarkan kajian pustaka dan kerangka pemikiran, maka dapat dikembangkan hipotesis penelitian sebagai berikut:

$\mathrm{H}_{1}$ : Pemahaman Peraturan Perpajakan berpengaruh positif secara parsial terhadap Kepatuhan Wajib Pajak.

$\mathrm{H}_{2}$ : Tarif Pajak berpengaruh positif secara parsial terhadap Kepatuhan Wajib Pajak.

$\mathrm{H}_{3}$ : Kualitas Pelayanan berpengaruh positif secara parsial terhadap Kepatuhan Wajib Pajak.

$\mathrm{H}_{4}$ : Pemahaman Peraturan Perpajakan, Tarif Pajak, dan Kualitas Pelayanan berpengaruh secara simultan terhadap Kepatuhan Wajib Pajak. 


\section{METODE PENELITIAN}

Penelitian ini dirancang untuk meneliti kepatuhan Wajib Pajak dan faktorfaktor yang mempengaruhinya. Penelitian ini dilakukan di KPP Pratama Cibinong. WPOP Non Karyawan yang tercatat Wajib SPT merupakan populasi penelitian. Convenience sampling merupakan teknik sampling yang digunakan pada penelitian, yaitu siapa saja yang secara kebetulan berpapasan dengan peneliti dan sesuai dengan karakteristik untuk sumber data, maka orang tersebut akan dijadikan sebagai sampel (Sugiyono, 2017), sehingga diperoleh jumlah sampel sebanyak 72 responden. Sumber data yang digunakan merupakan data primer melalui penyebaran kuesioner kepada Wajib Pajak dan data sekunder yang bersumber dari laporan KPP Pratama Cibinong. Data dari hasil kuesioner akan diolah dengan bantuan software SPSS Statistics 23. Analisis statistik deskriptif data responden dan regresi linier berganda digunakan pada penelitian ini. Persamaan regresi sebagai berikut:

$$
Y=\alpha+\beta_{1} X_{1}+\beta_{2} X_{2}+\beta_{3} X_{3}+e
$$

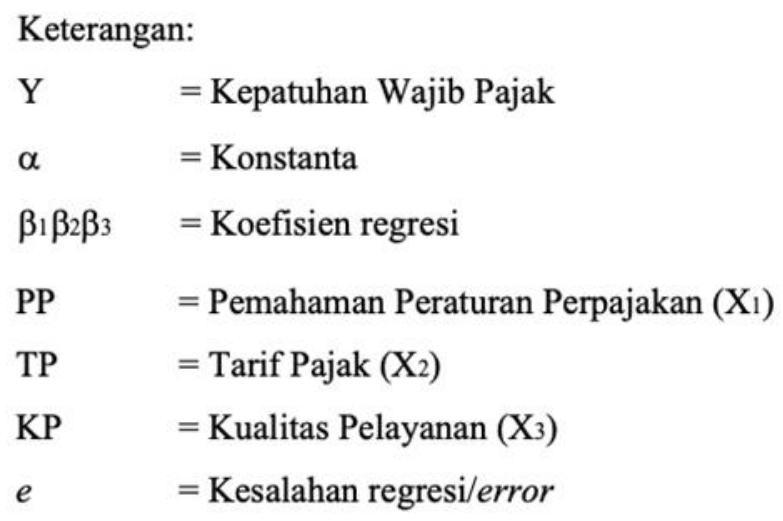




\section{HASIL DAN PEMBAHASAN}

Karakteristik responden sebagai berikut: 1) Berdasarkan jenis kelamin, 41 orang (57\%) adalah laki - laki; 2) Berdasarkan usia, mayoritas Wajib Pajak berusia 20 - 35 tahun sebanyak 50 orang $(69 \%)$; 3) Berdasarkan pendidikan terakhir, 33 orang (46\%) berpendidikan D3 dan S1; 4) Berdasarkan sumber penghasilan yang terdiri dari 2 sumber, Wajib Pajak didominasi dari pekerjaan bebas sebanyak 39 orang (54\%), sedangkan dari kegiatan usaha sebanyak 33 orang (46\%).

Hasil uji statistik deskriptif untuk variabel Pemahaman Peraturan Perpajakan $\left(\mathrm{X}_{1}\right)$ sebesar $84,14 \%$. Berarti Wajib Pajak sangat memahami ketentuan dan peraturan perpajakan dengan baik. Tetapi masih terdapat 13 orang (18\%) yang kurang memahami batas akhir penyampaian SPT Tahunan, dan 15 orang (21\%) yang kurang memahami sistem perpajakan yang diberlakukan saat ini.

Hasil uji statistik deskriptif untuk variabel Tarif Pajak $\left(\mathrm{X}_{2}\right)$ sebesar 79,01\%. Berarti Wajib Pajak memiliki persepsi terhadap tarif pajak dengan baik. Tetapi masih dijumpai 32 orang (44\%) yang beranggapan tarif pajak kurang adil untuk setiap Wajib, 28 orang (39\%) yang kurang mengetahui atau hanya cukup tahu bahwa tarif yang diberlakukan untuk Wajib Pajak Orang Pribadi adalah PPh pasal 17, dan 23 orang (32\%) yang beranggapan tarif pajak kurang disesuaikan dengan kondisi ekonomi Negara.

Hasil uji statistik deskriptif untuk variabel Kualitas Pelayanan $\left(\mathrm{X}_{3}\right)$ sebesar 86,57\%. Berarti pelayanan yang diberikan kepada Wajib Pajak memiliki kualitas 
sangat baik. Seluruh tanggapan responden mengenai kualitas pelayanan di KPP Pratama Cibinong mencapai di atas $80 \%$. Hal ini menunjukkan bahwa pelayanan serta petugas pajak di KPP Pratama Cibinong memiliki kualitas sangat baik.

Hasil uji statistik deskriptif untuk variabel Kepatuhan Wajib Pajak (Y) sebesar 82,90\%. Berarti Wajib Pajak patuh dalam melaksanakan kewajiban perpajakannya. Tetapi masih terdapat 20 orang (28\%) yang kurang mampu serta memahami cara menghitung dan memperhitungkan pajak.

Tabel 2.

Hasil Pengujian Secara Parsial (Uji Statistik t)

\begin{tabular}{|c|c|c|c|c|c|c|}
\hline & \multirow{2}{*}{ Model } & \multicolumn{2}{|c|}{ Unstandardized Coefficients } & \multirow{2}{*}{$\begin{array}{c}\text { Standardized Coefficients } \\
\text { Beta }\end{array}$} & \multirow{2}{*}{$\mathrm{t}$} & \multirow{2}{*}{ Sig. } \\
\hline & & B & Std. Error & & & \\
\hline \multirow{4}{*}{1} & (Constant) & 15.992 & 5.042 & & 3.172 & .002 \\
\hline & (X1) & .112 & .099 & .126 & 1.132 & .262 \\
\hline & (X2) & .285 & .115 & .283 & 2.480 & .016 \\
\hline & (X3) & .225 & .091 & .272 & 2.481 & .016 \\
\hline
\end{tabular}

Sumber: Output SPSS 23 (2020).

Berdasarkan Tabel 2, dapat dirangkai persamaan regresi:

$$
Y=15,992+0,112 X_{1}+0,285 X_{2}+0,225 X_{3}
$$

Pada persamaan regresi, diperoleh nilai konstanta $(\alpha)$ sebesar 15,992 dengan nilai Sig sebesar 0,002 lebih kecil dari $\alpha=0,05$. Jika diasumsikan, variabel independen yang terdiri dari pemahaman peraturan perpajakan $\left(\mathrm{X}_{1}\right)$, tarif pajak $\left(\mathrm{X}_{2}\right)$, dan kualitas pelayanan $\left(\mathrm{X}_{3}\right)$ sama dengan 0 atau bernilai konstan, maka variabel Kepatuhan Wajib 
Pajak sebesar 15,992. Berarti tanpa ada variabel lain yang mempengaruhi, Wajib Pajak sudah memiliki kesadaran untuk patuh.

Pengaruh Pemahaman Peraturan Perpajakan terhadap Kepatuhan Wajib Pajak. Berdasarkan Tabel 3, diketahui nilai koefisien regresi dari variabel pemahaman peraturan perpajakan $\left(\beta_{1}\right)$ sebesar 0,112 dengan nilai Sig sebesar 0,262 lebih besar dari $\alpha=0,05$. Berarti pemahaman peraturan perpajakan tidak berpengaruh terhadap kepatuhan Wajib Pajak. Hasil penelitian ini tidak sejalan dengan hipotesis penelitian, serta tidak mendukung hasil penelitian yang menyatakan bahwa pemahaman peraturan perpajakan berperngaruh terhadap kepatuhan Wajib Pajak (As'ari \& Erawati, 2018; Priambodo, 2017).

Jika dikaitkan dengan data penelitian menunjukkan bahwa masih dijumpai Wajib Pajak yang kurang memahami batas akhir dalam melaporkan SPT tahunan, serta kurang memahami sistem perpajakan yang diberlakukan bahwa Wajib Pajak diberi wewenang untuk menghitung, membayar, dan melaporkan sendiri pajak yang terutang. Artinya, semakin tinggi atau rendahnya Wajib Pajak mengetahui dan memahami peraturan perpajakan, tidak menentukan Wajib Pajak untuk patuh dalam melaksanakan kewajiban perpajakannya.

Pengaruh Tarif Pajak terhadap Kepatuhan Wajib Pajak. Koefisien regresi dari variabel tarif pajak $\left(\beta_{2}\right)$ sebesar 0,285 dengan nilai Sig sebesar 0,016 lebih kecil dari $\alpha$ $=0,05$. Berarti tarif pajak berpengaruh positif terhadap kepatuhan Wajib Pajak. Hasil penelitian ini sejalan dengan hipotesis penelitian, serta mendukung hasil penelitian 
yang menyatakan bahwa tarif pajak berpengaruh positif terhadap kepatuhan Wajib Pajak (Tawas dkk, 2016; Ananda dkk, 2015).

Berdasarkan hasil penelitian, persepsi Wajib Pajak terhadap tarif pajak tergolong baik. Artinya, Wajib Pajak memahami bahwa tarif pajak yang diberlakukan disesuaikan dengan penghasilan yang diperoleh Wajib Pajak. Selain itu, Wajib Pajak juga mengetahui berapa jumlah pajak yang harus dibayarkan. Semakin Wajib Pajak memahami persepsi atas tarif pajak yang diberlakukan, Wajib Pajak akan semakin patuh dalam melaksanakan kewajiban perpajakannya.

Pengaruh Kualitas Pelayanan terhadap Kepatuhan Wajib Pajak. Koefisien regresi dari variabel kualitas pelayanan $\left(\beta_{3}\right)$ sebesar 0,225 dengan nilai Sig sebesar 0,016 lebih kecil dari $\alpha=0,05$. Berarti kualitas pelayanan berpengaruh positif terhadap kepatuhan Wajib Pajak. Hasil penelitian ini sejalan dengan hipotesis penelitian, serta mendukung hasil penelitian yang menyatakan bahwa kualitas pelayanan berpengaruh positif terhadap kepatuhan Wajib Pajak (Susmita, 2016; Erlina dkk, 2018).

Berdasarkan hasil penelitian, pelayanan yang diberikan petugas pajak kepada Wajib Pajak tergolong sangat baik. Artinya, pelayanan yang diberikan petugas pajak memiliki kualitas yang sangat baik, sehingga Wajib Pajak timbul rasa puas dan kepercayaan atas pelayanan perpajakannya. Semakin berkualitas pelayanan yang diberikan, semakin meningkatnya kepatuhan Wajib Pajak.Pengujian secara simultan mengukur nilai koefisien determinasi $\left(\mathrm{R}^{2}\right)$ dan uji statistik $\mathrm{F}$ sebagai berikut: 
Tabel 3.

Hasil Analisis Koefisien Determinasi

\begin{tabular}{ccccc}
\hline Model & $\mathrm{R}$ & $\mathrm{R}$ Square & Adjusted R Square & Std. Error of the Estimate \\
\hline 1 &, $491^{\mathrm{a}}$ &, 241 &, 207 & 3,303 \\
\hline Sumber: Output SPSS $23(2020)$.
\end{tabular}

Tabel 4.

Hasil Uji Statistik F

\begin{tabular}{ccccccc}
\hline \multicolumn{2}{l}{ Model } & Sum of Squares & df & Mean Square & F & Sig. \\
\hline 1 & Regression & 235.252 & 3 & 78.417 & 7.186 &, $000^{\mathrm{b}}$ \\
\hline & Residual & 742.026 & 68 & 10.912 & & \\
\hline Total & 977.278 & 71 & & & \\
\hline
\end{tabular}

Sumber: Output SPSS 23 (2020).

Tabel 3 dan Tabel 4 menunjukkan nilai adjusted $R$ Square sebesar 0,207 dengan

nilai Sig sebesar 0,000 dari $\alpha=0,05$, berarti pemahaman peraturan perpajakan, tarif pajak, dan kualitas pelayanan mampu menjelaskan kepatuhan Wajib Pajak (Y) sebesar 20,7\%. Selebihnya dijelaskan oleh faktor lain di luar yang diteliti. Dengan kata lain, pemahaman peraturan perpajakan, tarif pajak, dan kualitas pelayanan secara simultan berpengaruh terhadap kepatuhan Wajib Pajak.

\section{SIMPULAN DAN SARAN}

Berdasarkan hasil analisis, dapat disimpulkan bahwa secara parsial yang berpengaruh positif terhadap kepatuhan Wajib Pajak hanya tarif pajak dan kualitas pelayanan. Sementara itu, pemahaman peraturan perpajakan, tarif pajak, dan kualitas pelayanan secara simultan berpengaruh terhadap kepatuhan Wajib Pajak. Penelitian ini memiliki keterbatasan dengan nilai koefisien determinasi yang rendah sebesar $20,7 \%$. 
Dengan demikian, masih terdapat variabel lain di luar yang diteliti, yang diduga berpotensi memiliki pengaruh terhadap kepatuhan Wajib Pajak.

Bagi Wajib Pajak, disarankan untuk meng-update pengetahuan mengenai peraturan perpajakan, karena masih dijumpai Wajib Pajak yang kurang mengetahui kapan batas akhir waktu untuk melaporkan SPT sehingga Wajib Pajak dapat melaporkan SPT tepat pada waktu yang ditentukan. Bagi KPP Pratama Cibinong, disarankan untuk mengadakan kegiatan sosialisasi perpajakan kepada Wajib Pajak mengenai: 1) peraturan dan tata cara perpajakan, untuk meningkatkan pemahaman Wajib Pajak bagaimana cara menghitung, memperhitungkan, dan melaporkan sendiri besar pajaknya, sehingga Wajib Pajak dapat mengisi SPT dengan benar sesuai ketentuan yang berlaku; dan 2) tarif pajak, untuk meningkatkan persepsi Wajib Pajak mengenai tarif pajak yang diberlakukan di Indonesia serta pemahaman mengenai jenis tarif pajak untuk setiap kelompok Wajib Pajak.Bagi Dirjen Pajak (DJP), disarankan untuk mengkaji kembali kebijakan tarif pajak selanjutnya bagi Wajib Pajak terutama Wajib Pajak Orang Pribadi, karena masih dijumpai Wajib Pajak yang menganggap tarif pajak yang diberlakukan belum sepenuhnya adil dan sesuai dengan kondisi ekonomi Negara. Berdasarkan simpulan dan keterbatasan dalam penelitian ini, bagi peneliti selanjutnya disarankan untuk meneliti kembali pada kelompok Wajib Pajak yang sama dengan menggunakan variabel lain, sebagai contoh: kesadaran Wajib Pajak; dan persepsi Wajib Pajak terhadap Sistem E-Filling. 


\section{REFERENSI}

Ananda, P. R., Kumadji, S., \& Husaini, S. (2015). Pengaruh Sosialisasi Perpajakan, Tarif Pajak, dan Pemahaman Perpajakan Terhadap Kepatuhan Wajib Pajak (Studi pada UMKM yang Terdaftar sebagai Wajib Pajak di Kantor Pelayanan Pajak Pratama Batu). Jurnal Perpajakan (JEJAK), 6, 1 - 9.

As'ari, N. G., \& Erawati, T. (2018). Pengaruh Pemahaman Peraturan Perpajakan, Kualitas Pelayanan, Kesadaran Wajib Pajak dan Sanksi Pajak Terhadap Kepatuhan Wajib Pajak Orang Pribadi (Studi Empiris pada Wajib Pajak Orang Pribadi Kecamatan Rongkop). Akuntansi Dewantara, 46 - 55.

Direktur Jenderal Pajak. (2013). Surat Edaran Direktur Jenderal Pajak Nomor SE09/PJ/2013 tentang Panduan Pelayanan Prima Direktorat Jenderal Pajak. Jakarta: Direktorat Jenderal Pajak.

Erlina, E., Ratnawati, V., \& Andreas. (2018). Pengaruh Kualitas Pelayanan Fiskus, Sanksi Pajak Terhadap Kepatuhan Wajib Pajak Orang Pribadi Non Karyawan: Kondisi Keuangan dan Pengetahuan Wajib Pajak Sebagai Variabel Moderating (Studi Empiris pada WPOP Non Karyawan di Wilayah KPP Pratama Bengkalis). Jurnal Akuntansi, 7, 42 - 57.

Friana, H. (2019, Desember 19). Tinggal Sebulan, Penerimaan Pajak 2019 Masih Kurang Rp474 Triliun. Retrieved Desember 25, 2019, from tirto.id: https://tirto.id/tinggal-sebulan-penerimaan-pajak-2019-masih-kurang-rp474triliun-enT2

Lazuardini, E. R. (2018). Pengaruh Pemahaman Peraturan Perpajakan, Tarif Pajak, Dan Sanksi Pajak Terhadap Kepatuhan Wajib Pajak UMKM (Studi Pada Wajib Pajak Orang Pribadi yang Terdaftar di KPP Pratama Malang Selatan). E-Jurnal Riset Manajemen Unisma, 7, 25-34.

Lubis, R. H. (2017). Pengaruh Kualitas Pelayanan Perpajakan, Dan Sanksi Perpajakan Terhadap Kepatuhan Wajib Pajak di KPP Pratama Medan Belawan. Jurnal Konsep Bisnis dan Manajemen, 4, 31-41.

Mahfud. (2017). Pengaruh Pemahaman Peraturan Perpajakan, Kesadaran Membayar Pajak, dan Kualitas Pelayanan Perpajakan Terhadap Kepatuhan Wajib Pajak Badan (Studi Empiris pada Koperasi di Kota Banda Aceh). Jurnal Magister Akuntansi Pascasarjana Universitas Syiah Kuala, 6, 1 - 9.

Mustofa, F. A. (2016). Pengaruh Pemahaman Peraturan Perpajakan, Tarif Pajak, Dan Asas Keadilan Terhadap Kepatuhan Wajib Pajak (Studi pada Wajib Pajak Usaha 
Mikro Kecil dan Menengah yang Berada di Wilayah Kerja KPP Pratama Batu Setelah Diberlakukannya Peraturan Pemerintah Nomor 46 Tahun 2013). Jurnal Perpajakan (JEJAK), 8, 1-7.

Pratiwi, P. S. (2016). Pengaruh Pemahaman Peraturan, Administrasi, Dan Sanksi Perpajakan Pada Kepatuhan Wajib Pajak Hotel di Kota Denpasar. E-Jurnal Akuntansi Universitas Udayana, 16, 1771-1799.

Priambodo, P. (2017). Pengaruh Pemahaman Peraturan Pajak, Sanksi Perpajakan, dan Kesadaran Wajib Pajak Terhadap Kepatuhan Wajib Pajak Orang Pribadi di Kantor Pelayanan Pajak Pratama Kabupaten Purworejo Pada Tahun 2017. Jurnal Profita, 5, 1-16.

Rahayu, S. K. (2017). Perpajakan (Konsep dan Aspek Formal). Bandung: Rekayasa Sains.

Salsabila, A. L., Majidah, \& Kurnia. (2019). Pengaruh Konservatisme Akuntansi, Profitabilitas dan Ukuran Perusahaan Terhadap Tax Avoidance (Studi Kasus Pada Perusahaan Makanan dan Minuman yang Terdaftar di Bursa Efek Indonesia Periode 2013-2017). e-Proceeding of Management, 6, 3364-3370.

Sugiyono. (2017). Metode Penelitian Kuantitatif. Bandung: Alfabeta.

Susmita, P. R. (2016). Pengaruh Kualitas Pelayanan, Sanksi Perpajakan, Biaya Kepatuhan Pajak, dan Penerapan E-Filling Pada Kepatuhan Wajib Pajak. EJurnal Akuntansi Universitas Udayana, 14, 1239 - 1269.

Suwiknyo, E. (2019, Agustus 7). Hingga Juli 2019, Kepatuhan Wajib Pajak Baru 67,2 Persen. Retrieved Desember 25, 2019, from Bisnis.com: https://ekonomi.bisnis.com/read/20190807/259/1133668/hingga-juli-2019kepatuhan-wajib-pajak-baru-672-persen

Tawas, V. J., Poputra, A., \& Lambey, R. (2016). Pengaruh Sosialisasi Perpajakan, Tarif Pajak, dan Sanksi Perpajakan Terhadap Kepatuhan Pelaporan SPT Tahunan Wajib Pajak Orang Pribadi (Studi Kasus Pada KPP Pratama Bitung). Jurnal EMBA, 4, 912 - 921. 